\title{
Pregnancy and Childbirth in COVID-19 Positive/Probable and Suspected Patients: A Comprehensive Review
}

\author{
MR BEGUM $^{\mathrm{a}}$, NEHSAN ${ }^{\mathrm{b}}$, MEHSAN $^{\mathrm{c}}$, AB SHARIF $^{\mathrm{d}}$
}

\begin{abstract}
Summary:
Corona virus disease 2019 (COVID-19) is a global pandemic disease caused by novel corona virus called SARS-CoV-2. Over 213 countries as of July 15, 2020, 13.1 million people are affected by this deadly virus. More than 100 million women are pregnant worldwide and potentially all are at risk of exposure to SARS-CoV-2 infection. Coronaviruses cause illness ranging in severity from common cold and severe respiratory illness to death. Frequent manifestations of COVID-19 include fever, cough, myalgia, headache, and diarrhoea. Abnormal test result shows abnormalities on chest radiographic imaging, lymphopenia, leukopenia, and thrombocytopenia. Physiological changes during pregnancy like altered immunity, reduced functional residual volume, pressure on diaphragm by advanced gravid uterus maylead to adverse respiratory outcome in any viral disease. Maternal mortality was very high in other corona viruses like Severe acute respiratory syndrome (SARS) and Middle East respiratory syndrome (MERS). No evidence of in utero
\end{abstract}

Introduction:

The novel coronavirus (SARS-CoV-2) is a new strain of coronavirus causing COVID-19, first detected in Wuhan city, the capital of Hubei province, China ${ }^{1}$. At the end of 2019, the virus appears to have originated in Wuhan and by $1^{\text {st }}$ week of January it rapidly spread to other countries of Asia, Europe and North America ${ }^{2}$. On $11^{\text {th }}$ March 2020 WHO announced COVID-19 outbreak as a pandemic. Scientist of China identified the virus as a new one and gave the name 2019-nCoV for 2019 novel coronavirus $^{3,4}$. Subsequently the World Health Organization (WHO) named the disease as Coronavirus

a. Mosammat Rashida Begum, Chief Consultant, Infertility Care and Research Center (ICRC) Ltd

b. Nazia Ehsan, Medical Officer, Infertility Care and Research Center (ICRC) Ltd

c. Mariya Ehsan, Medical Officer, Infertility Care and Research Center (ICRC) Ltd

d. Azaz Bin Sharif, Assistant Professor (LD), Department of Statistical and Actuarial Science, Western University, Canada

Address of Correspondence: Mosammat Rashida Begum, Chief Consultant, Infertility Care and Research Center (ICRC) Ltd, E-mail: rashida_icre@yahoo.com transmission was seen in SARS or MERS. Coronavirus disease 2019 might increase the risk of vertical transmission and pregnancy complications. So, meticulous management is necessary for safe maternal and foetal outcome. Early isolation, aggressive infection control procedures, oxygen therapy are the key component of COVID-19 management. In pregnancy multidisciplinary approach should be taken for general and obstetrical management. At present there is no specific treatment for COVID-19. Based on results from observational studies empiric antibacterial and antiviral drugs are used. Very recently a few controlled trials were published that suggest few treatment options. On the basis of published data and recommendations of international health organizations, the aim of this review is to explore effective treatment and care of the pregnant women throughout pregnancy, during childbirth and afterwards in this novel SARS-CoV-2 crisis.

Keywords: COVID-19, Pregnancy, Childbirth.

(J Bangladesh Coll Phys Surg 2020; 38: 91-108) DOI: https://doi.org/10.3329/jbcps.v38i0.47443

Disease -19 (COVID-19) ${ }^{5}$ and the international Committee of Taxonomy of viruses gave the name of the virus as SARS-CoV- $2^{6}$. This highly contagious disease causes severe acute respiratory distress syndrome (SARS) due to pneumonia. Pneumonia arising from any infectious aetiology is an important cause of morbidity and mortality. During the rapid spread of COVID-19 all over the world SARS-CoV-2 infection in pregnant women is inevitable. Due to changing immune system pregnant women may be more vulnerable to any severe infection. Evidence from other similar viral illness such as influenza A/H1N1, ${ }^{7-10}$ SARS-CoV ${ }^{11}$ and MERS$\mathrm{CoV}^{12,13}$ suggests that pregnant women are at greater risk of severe maternal and neonatal morbidity and mortality. The rate of critical illness may be the highest in the later stage of pregnancy $7,12,13$. Lots of evidence of the effect of COVID-19 on pregnancy and childbirth have already been published from different corners of the world within this short span of the disease. The purpose of this review is to gather the effects of SARS$\mathrm{CoV}-2$ infection in pregnancy and childbirth and recommendations of different organizations for effective management of the patient. 


\section{Mode of transmission of SARS-CoV-2 from mother to baby:}

Infectious agent like bacteria and viruses can transmit from mother to baby through placenta, during delivery through birth passage or through mother's milk. Another rare possibility of viral transmission to developing embryo through male gamete called reproductive transmission.

\section{Vertical Transmission:}

When any pathogen such as bacteria and virus that is transmitted directly from mother to an embryo, foetus or baby during pregnancy or childbirth is called vertical transmission. It may occur when mother gets infected during pregnancy. SARS-CoV-2 is a virulent virus causes multiorgan pathologies of infected person. When pregnant mother is infected then there is a possibility of passing the virus to the growing baby through placenta (transplacental) and causing serious birth defects, foetal growth restriction, premature labour or foetal death. So, it is very important to know whether SARS-Cov-2 virus can affect the baby in the uterus or not. When a baby is contracted infection during delivery there will be no serious effect of growth and development of the baby but baby will be considered as a patient of COVID-19

\section{Transplacental transmission:}

A number of studies analyzed 30 COVID-19 patients in the third trimester and 29 of them gave birth 30 babies with one set of twins. Pharyngeal swab specimens were collected from 22 of 30 babies, all ${ }^{14-17}$ were negative for RT-PCR for SARS-CoV-2 except one ${ }^{17}$ which was positive 36 hours after birth. Amniotic fluid, umbilical cord blood were tested but no SARS-CoV-2 was found. Almost all samples of amniotic fluid, cord blood, neonatal throat swab were collected immediately after delivery in the operating room. It indicates that vertical transmission from mother to baby does not occur. One neonate who was positive 36 hours after birth, possibly due to transmission from outside environment. Another 5 neonates born to COVID-19 pregnant women tested positive to SARS CoV-2, but in all cases whether they were isolated from mother or not was not certain ${ }^{18-20}$. In one neonate RT-PCR of nasal and throat swabs was done just after delivery, which was negative. However, the second test was positive 24 hours later. She was kept in the isolated NICU without any contact with her mother after birth. The infant was given powdered milk as a substitute of breast milk. Mother's RT-PCR test for COVID-19 was positive for amniotic fluid but was negative for umbilical cord blood. This is the only case where amniotic fluid was positive in-spite of negative test for neonate ${ }^{21}$. But positive test after 24 hours may be due to transmission from other staffs than mother as she was isolated from mother.

Three infants born to mothers with COVID-19 had elevated IgM antibodies to SARS-CoV-2 ${ }^{22,23}$. They were delivered in the negative pressure isolation room and mothers wore masks during delivery where chance of cross infection was almost nil. Infants were isolated immediately after delivery. One infants test was done 2 hours after delivery. All mothers' IgM and IgG were raised. IgG and cytokines also raised in all three newborns. IgG can cross the placenta ${ }^{24}$ but due to larger molecular weight IgM cannot cross the placenta ${ }^{25}$. So, presence of IgM immediate after birth indicates intrauterine infection as it takes 3-7 days to appear IgM after any infection. RTPCR of all babies were negative and in one baby it was negative from 2 hours to 16 days $^{23}$. On the other hand, IgG appears later than IgM. Therefore, elevated IgG level may reflect maternal or foetal infection. Though negative RT-PCR test result of nasopharyngeal swab failed to explain the presence of $\operatorname{IgM}$ in the newborn. In one study placenta of two women having SARS infection found with abnormal weight and pathology ${ }^{26}$. May be in these cases placentas were pathological to allow IgM to pass or IgM could have been produced by the infant if the virus crossed the placenta. More such cases are needed to draw the conclusion.

Christina et al tested placental or membrane swabs from 11 patients and three of 11 swabs were positive for SARSCoV-2 infection in moderate to severe ill COVID-19 patients. All infant's nasopharyngeal swabs were tested between D1 and D5. None of the infants tested positive for SARS-CoV-2 and none demonstrated symptoms of COVID-19 infection. The presence of viral RNA by RTPCR in placenta/membranes suggests the possibility of vertical transmission ${ }^{27}$. Although neonatal nasopharyngeal swab testing immediately after delivery was negative, it cannot exclude intrapartum transmission as the virus may require a longer incubation period before these swabs convert to positive. In contrast Zeng et al described very low expression of ACE2 in almost all human cell types of early maternal fetal interface, suggesting the placenta had virtually no susceptible cells to the virus ${ }^{22}$. Another case report shows positive RT-PCR in fetal side of placenta in mother of two RT-PCR positive babies. Nasopharyngeal swab was taken immediately after birth and one shows positive at birth, at 24 hours and after 7 days who was allowed for breast feeding only without skin to skin 
contact and mother was on face mask. Another baby was totally isolated from mother whose nasopharyngeal swab was negative immediately after birth but came positive at 7 th day of birth. Both were fine except minor feeding difficulties. So, author did not give any conclusion of vertical transmission except raising the suspicion of transmission ${ }^{28}$.

A large series of 116 cases reported that there is no evidence of vertical transmission of SARS-CoV-2 infection when the infection manifests during the third trimester of pregnancy ${ }^{29}$. But the latest report in Medscape Medical News mentioned that Fenizia and colleagues from Italy shows 2 positive babies for SARSCoV-2 infection out of 31 COVID-19 positive women. In this report both $\operatorname{IgM}$ and $\operatorname{IgG}$ were present in both maternal blood and foetal cord blood in one baby and only IgG in other baby. RT-PCR was positive in all (amniotic fluid, placenta, vaginal swab, umbilical cord and nasopharyngeal swab of babies) samples from mothers and babies. It indicates that it is possible in utero SARS-CoV-2 transmission (Medscape Jul 10, 2020).

During this COVID-19 period no babies were born whose mothers were infected during their first trimester. So, there is no evidence about outcome of $1^{\text {st }}$ trimester infection. Out of 116 cases reported by Yan et al one case of $1^{\text {st }}$ trimester ended by missed abortion, but product of conception was not tested. Further research may explore the possibility of vertical transmission and the cause of missed abortion.

Regarding $2^{\text {nd }}$ trimester affection Yan et $\mathrm{al}^{29}$ reported ( 8 cases) one missed abortion and other ongoing pregnancies having good morphology at ultrasound in 4 cases who reached to 20 weeks. Examination of placenta of another case of 22 weeks missed abortion shows SARS-CoV-2 spike protein, demonstrating viral localization predominantly in syncyto-trophoblast cells. In situ analysis for the presence of SARS-CoV-2 RNA shows strong positive staining within the placenta ${ }^{30}$. The patient was a case of hypertensive disorder of pregnancy. Whether missed abortion was due to hypertensive disorder of pregnancy or the effect of COVID-19 is not clear. Analysis of placental region adjacent to the umbilical cord identified virus particles within the cytosol of placental cells. The size of these virus particles was $75-100 \mathrm{~nm}$ in diameter, which is consistent with the size and appearance of SARS-CoV$2^{31}$. In another case placental submembrane and cotyledon biopsies tested positive for SARS-CoV-2 infection in placenta of 18 weeks miscarried case. The umbilical cord, amniotic fluid, fetal mouth, armpit, anus, liver, thymus, and lung tested negative ${ }^{32}$. So, in-spite of placental involvement foetus was not involved and COVID-19 may not be the responsible factor for abortion.

\section{Transmission during vaginal delivery:}

In a few studies vaginal fluid was tested for RT-PCR to observe the chance of transmission through vaginal fluid during delivery. In all cases negative vaginal fluid test suggest that virus also cannot pass through vaginal secretion of COVID-19 patients $^{21,23,33,34}$. Though an Italian report shows positive RT-PCR of vaginal swab in 2 cases of COVID-19 women, where both babies were also positive, but mode of delivery was not mentioned (Medscape-Jul10,2020).

\section{Reproductive transmission:}

SARS-COV-2 RNA is detected in 6/38 semen samples (sperm) of COVID-19 positive men. Four (4) of them was in acute stage and 2 were in a stage of recovery. Though viability and clinical relevance is unclear, there still remains a possibility of sexual transmission ${ }^{35}$. Wang and Xu found that ACE2 was remarkably upregulated in spermatogonia, Leydig and Sertoli cells ${ }^{36}$. Moreover, TMPRSS2 and ACE2 expression in Leydig and Sertoli cells and ovary, suggest a high penetration of SARSCov-2 infection in human Testes and ovary ${ }^{37}$.

\section{Transmission through breast milk:}

Evidence also shows that SARS-CoV-2 virus also can not pass through breast milk. Breast milk was collected after first lactation of the mother and tested for RT-PCR shows negative result indicates that transmission can not occur through breast milk ${ }^{15,18,23}$.

\section{Pathophysiology:}

Based on clinical observation it is assumed that the virus might enter through nose and mouth and pass through mucus membrane of nose and larynx to lungs causing sore throat, cough, and fever ${ }^{38}$. The virus may also enter into the peripheral blood from the lungs causing viremia and attack those targeting organs which express ACE2 receptor through which virus can cause inflammation. The targeting organs are lungs, heart, 
renal, gastrointestinal tract, endothelial cells ${ }^{39,40}$. The most commonly affected organ is lungs causing pneumonia and ARDS about 8 days after onset of the symptoms ${ }^{41}$. The clinical phase can be divided into three; the viremia phase, the acute phase (pneumonia phase) and the recovery phase. If the immune function of the patient in acute phase is effective and there is no more basic diseases, the virus then effectively suppressed and enter into recovery phase. If the patient is older with other co-morbidities such as diabetes, hypertension the immune system cannot effectively control the virus in the acute phase and will become severe or critical type ${ }^{42}$. Due to the physiological changes in the immune and cardiopulmonary system pregnant women are also more likely to develop severe illness after respiratory viruses ${ }^{43}$. During the infection process the white cell count in peripheral blood in early stage of disease is normal or slightly $\operatorname{low}^{37}$ and lymphopenia is observed ${ }^{41}$. There is further and significant reduction of lymphocytes and continuous increment of cytokines and D-dimer in severe type of patients $^{42}$. The SARS-CoV-2 virus infects endothelial cells by binding to ACE-2. Cellular infection initiates localized inflammation, endothelial activation, tissue damage, and disordered cytokine release. The combination of observed physiology and emerging pathologic evidence points toward a vascular disease process as contributing factor in COVID-19 pathogenesis. Vascular disease may also explain massive D-dimer elevations, while antiphospholipid antibodies were recently reported in COVID-1944,45. Author concluded that COVID-induced respiratory failure involves physiologic, clinical, and immunologic phenotypes that are not consistent with either ARDS or cytokine-release syndromes rather reflect immunosuppression and features compatible with vascular disease ${ }^{45}$.

Patients of advanced age and with co-morbidities like diabetes, cardiovascular disease, hypertension, chronic pulmonary disease, liver disease, malignancy, immunocompromised state and severe obesity are more risky for aggressive pathology of SARS-CoV-2 infection $^{46-49}$.

Patients of diabetes, hypertension and cardiovascular disease who take drugs like ACE2 inhibitor or Angiotensin II receptor blockers (ARBs) increases the expression of the ACE2 mRNA by negative feedback mechanism ${ }^{50}$. Any agent that increases expression of ACE2 could potentially increase susceptibility to severe COVID-19 by improving viral cellular entry ${ }^{51}$. On the other hand ACE2 also converts angiotensin 2 to angiotensin 1-7, which leads to vasodilation and may protect against lung injury by lowering angiotensin 2 receptor binding ${ }^{52,53}$. It is therefore uncertain whether an increased expression of ACE2 receptors would worsen or mitigate the effects of SARSCoV-2 in human lungs.

\section{Presentations of SARS-CoV-2 infection:}

Many of the COVID-19 positive cases have no symptoms at all. Symptoms may develop 2 days to 2 weeks following exposure to the virus ${ }^{54}$. Symptomatic patients have mild symptoms to severe illness and mortality. Commonest symptoms are fever, cough, and shortness of breath ${ }^{55}$. Other features are chills, repeated shaking with chills, muscle pain, headache, sore throat, loss of taste or smell, fatigue, sputum production, diarrhoea, malaise, respiratory distress.

According to severity of symptoms patients are classifies into three category

- Mild: Cough, fever, myalgias, anosmia

- Moderate: Dyspnoea, chest imaging (sign pneumonia) ABGs- $\mathrm{O}_{2}$ saturation $>93 \%$, fever$\geq 39.0^{0} \mathrm{C}$

- Severe: RR: $>30 /$ minute, Hypoxia- $\mathrm{O}_{2}$ saturation $\leq 93 \%$, Pao2/Fio2-<300 mmHg, chest imaging- $>50 \%$ lung involvement

Disease is confirmed by positive RT-PCR. CT scan findings of lungs also gives the clue of atypical pneumonia.

COVID-19 disease categorized as

- Confirmed case: Woman has laboratory result confirmation for SARS-CoV-2.

- Probable case: Woman who has symptoms with positive antigen/antibody blood test but no confirmatory RT-PCR test

- Suspected case: Woman who has become symptomatic of a viral illness like a high temperature cough or loss or change of sense of smell or taste and COVID-19 is a part of the differential diagnosis and testing has been sent

- Contact: Woman is asymptomatic but was exposed to a Health Care Provider or family member who has become symptomatic for or diagnosed with COVID-19. 


\section{Effects of SARS-CoV-2 infection on mother:}

Though pregnant women are not necessarily more susceptible to viral illness, at the end of the gestation due to changing immune system in pregnancy severe symptom may develop if she gets infected. In a large unpublished data from 16,749 COVID-19 patients it is found that pregnancy was not associated with increased mortality in comparison to influenza ${ }^{56}$. Pneumonia is an important cause of morbidity and mortality among pregnant women ${ }^{57}$. Premature rupture membrane (PROM) and preterm labour (PTL), intrauterine fetal death (IUFD), intrauterine growth restriction (IUGR) and neonatal death are common complications of corona virus (SARS, MERS) infection ${ }^{58}$. But for these effects mother should be exposed to infection in her early pregnancy. Novel corona virus is new for human and much evidence are not available to observe all these effects as most recent deliveries are from patients who exposed to the infection at their $3^{\text {rd }}$ trimester. Now the question is; what might be the effect of COVID-19 on mother's health, as immunity is lower in pregnancy than non-pregnant women? There is no data to inform whether pregnancy increases susceptibility to COVID19 or not. Data from previous coronaviruses (SARS$\mathrm{CoV})^{11,59-62}$ and (MERS- CoV) ${ }^{63-68}$ suggest that pregnant women may be at higher risk of severe illness, morbidity and mortality compared with the general population. A case control study at Hong Kong reported that ICU requirement was $60 \%$ and case fatality rate (CFR) was $40 \%$ in SARS-CoV pregnant women which was very high in comparison to non pregnant SARSCoV women, which was $17.5 \%$ and $0 \%$ respectively ${ }^{61}$. In MERS ICU requirement was $64 \%$ and CFR was $27 \% 12$, 63-68. When compared with COVID-19 a small study of China showed that there was no mortality among 32 women and only 2 women required intensive care unit (ICU) admission and mechanical ventilation and one of whom developed multiorgan dysfunction and was on extracorporeal membrane oxygenation (ECMO) till the report $^{12}$. Another study from China also reported that out of 118 pregnant patients with COVID-19 in Wuhan, the risk of severe disease was not high $(8 \%)$ in comparison to the risk in the general population of patients in mainland China $(15.7 \%)^{69}$. No maternal death was reported in both studies.

A large series of very recent study of UKOSS shows that out of 427 pregnant women with confirmed COVID19 from 194 hospitals of UK 9\% patients needed critical care and $1 \%$ patient died. They compared with previous years 694 pregnant patients with influenza and found worse prognosis of COVID-19 patients than patient with influenza where only $<1 \%$ patients needed critical care and there was no death ${ }^{70}$. Two studies stated that severity of the disease of COVID-19 pregnant patient was lower than general population of COVID-1969,71.

Table-I

\begin{tabular}{|c|c|c|c|c|}
\hline Variables & $\begin{array}{c}\text { SARS-CoV-2 } \\
\text { China } \\
\text { N-150 }\end{array}$ & $\begin{array}{c}\text { SARS-CoV-2 } \\
\text { UKOSS } \\
\text { N-427 }\end{array}$ & $\begin{array}{c}\text { SARS-CoV } \\
\text { N-20 }\end{array}$ & $\begin{array}{l}\text { MERS } \\
\text { N-11 }\end{array}$ \\
\hline Maternal Age (yrs) (Range) & $28-34$ & $20-40$ & $24-44$ & $27-39$ \\
\hline GA in weeks & $25-39$ & $<20-39$ & $3-32$ & $6-38$ \\
\hline Maternal comorbidity N (\%) & $4 / 19(21)$ & $62(14.5)$ & NR & $5(45)$ \\
\hline Maternal ICU admission & $3 / 150(2 \%)$ & $40(9 \%)$ & $6(30 \%)$ & $7(64 \%)$ \\
\hline Maternal death & $0 / 150(0 \%)$ & $5 / 427(1 \%)$ & $3(15 \%)$ & $3(27 \%)$ \\
\hline Pregnancy loss \& still birth & $10 / 150(7 \%)$ & $7 / 247(3 \%)$ & $5(25 \%)$ & $2(18 \%)$ \\
\hline Delivery & $68 / 118(58 \%)$ & $243(57 \%)$ & NR & $\mathrm{NR}$ \\
\hline Caeserean section due to SARS-CoV-2 & $38 / 62(61 \%)$ & $39 / 243(16 \%)$ & NR & NR \\
\hline Premature birth & $29 / 100(29 \%)$ & $63 / 243(26 \%)$ & $4 / 13(31 \%)$ & $3(27 \%)$ \\
\hline Neonatal Death & $1 / 102(<1 \%)$ & $2 / 240(<1 \%)$ & $0 / 13(0 \%)$ & $1 / 11(9 \%)$ \\
\hline $\begin{array}{l}\text { Positive SARS-CoV-2 test in } \\
\text { liveborn baby only }\end{array}$ & $0 / 25(0 \%)$ & $12 / 240(5 \%)$ & $0(0 \%)$ & $0(0 \%)$ \\
\hline
\end{tabular}


We compared the effect of SARS-CoV-2 on mother reported from China and UK with SARS-CoV and MERS and observed that critical care and maternal death was much higher in SARS-CoV and MERS in comparison to SARS-CoV-2 (Table 1) ${ }^{12,59-71}$. Majority of patients were symptomatic (81\%) at admission and the commonest symptoms were fever, cough and breathlessness. Tiredness or weakness or lethargy, headache, limb or joint pain, body ache, sore throat, vomiting, diarrhoea and rinorrhoea were also presenting symptoms at admission. Black and other minority ethnicity (BAME) with preexisting co-morbidity, $>35$ years, GDM, multiple pregnancy and overweight were higher in number among admitted patients in UK. BAME pregnant women of UK had worst outcome. The most critical care patients were from BAME and these group were more likely to die from COVID-19 ${ }^{70}$. Though the exact cause is not clear, socioeconomic, genetic factor or difference in response to infection might be the cause ${ }^{70,72}$.

Pandemic has tremendous effect on mental health of the women. COVID-19 causes anxiety and stress due to fear of not getting support from family and friends due to social isolation and financial crisis due to static source of income. Most important issue is difficulty of getting antenatal services. COVID-19 infection in pregnant women is expected to impact obstetrical care severely. US assumes an increase in maternal mortality rate at least 18.7 deaths per 100000 livebirths as a direct result of COVID- $19^{73}$.

\section{Effects of SARS-CoV-2 infection on Baby:}

Almost all reports came from outcome of the $3^{\text {rd }}$ trimester pregnancy. Few abortions were noted in the $1^{\text {st }}$ and in the end of 2nd trimester but whether there was any effect of SARS-CoV-2 it was not certainly identified. Among $3^{\text {rd }}$ trimester babies both mature and premature babies were born. No adverse effect of SARS-CoV-2 was observed on babies. Many studies reported on the basis of negative RT-PCR of maternal amniotic fluid, placental membrane, umbilical cord, breast milk, vaginal fluid and fetal nasopharyngeal swab that there is either no or very little possibilities of vertical transmission of virus from mother to fetus ${ }^{14-17}$. Few studies shown positive RT-PCR test of newborn immediately after delivery with negative results of maternal samples ${ }^{17-20}$. In-spite of positive RT-PCR or presence of IgG or IgM in three fetuses none of them presented severe symptoms ${ }^{22,23}$. For majority of the babies 1 minute and 5 minutes Apgar score was 8-9 and 9-10 respectively ${ }^{17-}$ $20,22,23$. Nine articles reported imaging result of newborn. Five of the six SARS-CoV-2 positive newborns radiographic images shows pneumonia, increased lung marking, thickened texture or high-density nodular shadow $^{14,15,18,19,22,23,74-76 .}$ One reported a newborn with transient respiratory distress and low birth weight ${ }^{76}$, another ${ }^{74}$ reported 3 newborns with pneumonia, 2 of them presented fever and one preterm presented asphyxia at birth and respiratory distress syndrome. Zhu $\mathrm{H}^{14}$ reported that out of 10 newborns 6 showed shortness of breath and among them five were premature. Intrauterine fetal distress was found in mothers of four neonates but no severe neonatal asphyxia was noted. Fever and pediatric critical illness score (PCIS) of less than 90 was in two cases. Other symptoms like vomiting, edema, skin rash, fever, milk rejection and gastrointestinal bleeding were also reported. One series shows 3 cases of neonatal respiratory distress syndrome after birth, 2 of which were preterm babies ${ }^{72}$. Li and colleagues reported higher prevalence of preterm birth and low birth weight babies in COVID-19 patients than that of mothers of non COVID19 pneumonia but no significant differences in key indicators of those groups. UKOSS study shows higher prematurity in SARS-CoV-2 pregnant women $(26 \%)$ than patient with Flu $(8 \%)^{70}$. Two case series shows DIC in three neonates, possibly due to sepsis and immature immune function of the neonates ${ }^{14,19}$. One of them died of sepsis. Another neonatal death occurred within 2 hours of birth due to severe asphyxia, where mother developed severe pneumonia and septic shock ${ }^{28}$. So, it is predicted that the severity of neonatal symptoms is closely related to maternal condition and iatrogenic premature labour due to maternal indication ${ }^{14}$. It indicates that prematurity is not the direct effect of SARS-CoV-2 infection rather it is effect of maternal severity of illness by SARS-CoV-2 infection.

\section{Antenatal Care:}

To keep the women and baby safe throughout the pregnancy, during birth and afterwards, antenatal care (ANC) and post-natal care (PNC) is recommended based on years of experience. ANC and PNC are regarded as essential care for expecting mother even in this crisis of CVID-19 era where lockdown and social distancing are 
practicing unless she needs self-isolation. If women don't seek ANC they are at increased risk of maternal death, stillbirth and other adverse perinatal outcome.

Developed countries usually offer 7 to 11 regular prenatal visits throughout each pregnancy ${ }^{77}$. It is not like that they are at risk of development of complications like premature labour, low birth weight or preeclampsia, rather the women were less satisfied with fewer visits. But in low- and middle-income countries, perinatal mortality increased as the number of visits was reduced even if pregnant women were not at high risk group ${ }^{78}$.

But WHO rescheduled the antenatal visit (table 2) to reduce the possibility of exposure of a healthy pregnant woman to COVID-19 confirmed positive, probable or suspected patient and to reduce health care workers' exposure to asymptomatic COVID-19 positive cases.

To avoid exposure of both patient and care givers from COVID-19 schedule included both telemedicine and face to face contact.

1. Low-risk women need 8 contacts (virtual or inperson) in pregnancy with a healthcare provider.
Patients are advised to come to the facility when pain starts or at 41 weeks if no pain has started.

2. High risk patients need visit according to their physical and foetal condition. Both in-person and virtual care can be considered.

3. All laboratory tests and ultrasound tests that are time sensitive should still be completed i.e., dating US scan, 20-week US scan, diabetes screen, genetic screening, 35-37 week GBS screen ${ }^{81}$.

For low risk patients FIGO recommended 5 visits scheduled with testing. At 12 weeks for genetic screening, 20 weeks for the morphology scan and review, 28 weeks for gestational diabetes screening, anti-immunoglobulin administration and Tdap vaccination, 32 weeks, 36 weeks for Group B Streptococcus culture, and 38 weeks' appointment for risk assessment and birth planning 82 .

Advice can be given virtually about nutrition, routine activities, travelling, for minor ailments like nausea, vomiting, slight pain, insomnia, sex behavior, health care and maintaining hygiene like hand washing, cough etiquette, social distancing, wearing mask where needed.

\section{Table-II}

Recommendations for Prenatal Care Contacts during the COVID Pandemic (WHO) ${ }^{79,80}$

Contact 1: up to 12 weeks

Contact 2: 20 weeks

Contact 3: 26 weeks

Contact 4: 30 weeks

Contact 5: 34 weeks

Contact 6: 36 weeks

Contact 7: 38 weeks

Contact 8: 40 weeks
Face to face: Detailed history and examination, booking investigations, USG if available. Risk identification

Remote contact: Ongoing risk assessment. In case of missing $1^{\text {st }}$ in person contact, in-person contact is recommended

Remote contact: Ongoing risk assessment.

Face to face: BP/Blood tests and abdominal palpation including FHR. Ongoing risk assessment.

Remote contact: Ongoing risk assessment

Face to face: BP/Blood tests and abdominal palpation including FHR. Ongoing risk assessment. Birth planning

Remote contact: Unless risk factors for hypertension in pregnancy or growth restriction identified previously.

Face to face: BP/Blood tests and abdominal palpation including FHR. Ongoing risk assessment. Birth planning. 
Patient can check blood sugar, blood pressure and weight by family member and low risk patients can avail suggestion by telemedicine. In high risk cases to measure blood pressure, blood sugar, hemoglobin conc and weight in person consultation is necessary.

Schedule for ANC for confirmed, probable and suspected case with mild symptoms and contacts ${ }^{83-85}$

\section{i. For routine check-up:}

- Patient needs to be self-isolated herself at home at least 10 days after onset of symptoms.

- Women should notify the clinic via telephone about their self-isolation, appointment should then be reviewed for urgency and either rescheduling for tele or video-consultation or deferred for at least 14 days.

- Routine appointments for growth scan or screening for GDM should be delayed until and after the recommended period of self-isolation.

- She should take symptomatic treatment according to advice through tele or video-consultation. Each country has its own guideline based on reported evidence. Regarding drug there is debate and controversy of using hydroxychloroquine. A large study on 3016 COVID-19 cases (SOLIDARITY TRIAL) shows no benefit, rather increased frequency of ventricular arrythmia in comparison to control group $^{86}$.

- The Infectious Diseases Society of America (IDSA) has formed a multidisciplinary guideline panel to provide treatment recommendations for coronavirus disease 2019 (COVID-19) recommended hydroxychloroquine in the hospital setting only for clinical trial ${ }^{87}$.

- Aantibacterial, antiviral therapy is used according to each country's own protocol based on published data.

- Prophylactic dose of low molecular weight heparin (LMWH) can be started.

- Thromboprophylaxis must be continued, who already were on it.

- Patient should be tested for confirming recovery, if she goes outside for testing not to travel by public transport.
- Probable case should be advised for testing RT-PCR for confirming and not to travel by public transport.

- Suspected case should be advised for testing RTPCR for confirming and not to travel by public transport.

- Patient can return to regular activities after passing 10 days from onset of symptom, or at least 3 days have passed since resolution of fever without antipyretic and improvement in cough, shortness of breath, or after 2 consecutive negative result at least 24 hours apart

- Coughing may persist for several weeks, so coughing alone does not require to continue to isolate.

- An ultrasound scan is recommended at least 2 weeks after recovery, to check that baby is well.

- Patient should be counselled that there is no strong evidence of adverse effect on baby due to SARSCoV-2 infection.

- Patient also should be counselled that after recovery from coronavirus birth place and birth process will not be affected by previous illness.

- Contact should be quarantined for 14 days following same isolation rule and don't need to testing RTPCR if she does not develop any symptom.

\section{Health safety advice during isolation}

- Patient is advised to maintain strict health hygiene for COVID, like washing hands, maintaining cough etiquette.

- Visitors should not be allowed.

- Other family members should not go out even for buying food and medicine, which should be managed by online shopping or by outside family members or friends.

- Patient should be kept away from seniors and people with chronic medical conditions (e.g. diabetes, lung problems, heart disease or weakened immune system).

- Rooms should be well ventilated with open window.

- Separate themselves from other members and their household as far as possible, using their own towels, crockery and utensils and eating at different times, disposal of waste in a closed bucket. 
- Patient is advised to wear a mask.

- Other people should wear a mask and maintain a distance of at least 2 meters- when they are in the same room with suspected person.

- They are advised to take plenty of water and remained mobile throughout this period to prevent the risk of thromboembolism.

\section{ii. For emergency check-up during isolation}

- IfCOVID-19 positive or other isolated or quarantined cases have any obstetrical emergency like, less foetal movement, breaking water or per vaginal bleeding she should take emergency appointment for in person consultation.

- Midwife or doctor will made necessary arrangements for the patient and will advise to attend at a different time to protect others.

- $\quad$ For suspected, probable and confirmed COVID-19 patients it is advised to move via private transport if possible. They need to inform the ambulance call handler that she is currently in self isolation for COVID-19 positive, for suspicion or probability.

- Patient needs to alert the maternity unit reception or staff by telephone before going to the hospital so that staff can get prepared with PPE.

\section{When to admit into the hospital?}

- If symptoms are worsening, developing breathing difficulty or patient is not getting better or recovery is delayed, this may be a sign of developing a more significant chest infection that requires advanced care.

- If patient is at higher risk of becoming seriously unwell and if she is in her third trimester, age of $>35$, overweight or obese, or having co-morbidities as high blood pressure or diabetes. UKOSS recommended to give special emphasis to their black or minority ethnic background.

- If patient develops any obstetrical emergency or goes into labour during isolation.

\section{Screening of patients at facility:}

In the facility all patients should be screened by taking detailed history regarding travel, occupation, contact, cluster and symptoms. Women with risk factors but without a diagnosis of COVID-19 infection and symptom, appropriate measures should be taken as suspected COVID-19 management with advice of home quarantine. If there are symptoms, she should be tested for SARSCoV-2 infection and will be managed as mentioned above.

Precautions for health-care providers before in person consultation:

It is very important to follow the rules to reduce the rate or to prevent transmission between staff. They should follow the strict infection prevention rule. Staff should adhere to PPE guidelines and it is mandatory to make every effort to observe social distancing measures at work place, wearing medical grade mask, hand washing or using sanitizer, eating in a designated area, safe waste disposal and maintaining a distance of 2 meters between colleagues where practical. Staff should be prepared with full PPE to receive the patient along with fluid resistant surgical mask and should not be removed until the patient is isolated in a suitable room. Staff must be well trained about correct donning, doffing and disposal of personal protective equipment.

\section{Management of the patient in the hospital:}

Although the majority of people with COVID-19 have uncomplicated or mild illness (81\%), some will develop severe illness requiring oxygen therapy (14\%) and approximately $5 \%$ will require intensive care unit treatment. Of those critically ill, most will require mechanical ventilation ${ }^{88,89}$. The most common diagnosis in severe COVID-19 patients is severe pneumonia.

Most of the patients can be managed at home. Only patient with respiratory distress needs to be treated in the hospital. Confirmed and suspected or probable cases of COVID-19 should be isolated as soon as possible in an airborne infection isolation room (AIIR). If an AIIR is not available patient should be transferred to a hospital with an AIIR. Health care provider should be prepared with eye protection and properly fitted N95 respirator. Patient should be managed by multidisciplinary approach. Consultant obstetrician, maternal-fetal medicine specialist, intensive-care specialist, respiratory physician, consultant anesthetist, midwife- in charge, neonatal nurse in charge, infection control team, consultant neonatologist, all should be involved. Only essential personnel will remain with the patient to minimize the number of the staff.

In suspected and probable patient sample should be collected by appropriate personnel and is to be sent for 
diagnostic SARS-CoV-2 testing. Number of visitor should be minimum.

- Pregnancy should be considered as high risk for COVID-19 and both maternal and fetal condition should be monitored closely including fetal heart rate and uterine contraction.

- Following tests are to be done to recognize the severity of the disease. Full blood count, liver and renal function test, coagulation testing, D-dimer, blood urea nitrogen, CRP, Procalcitonin.

- Chest imaging specially CT scan of chest is essential for the evaluation of the unwell patient with COVID-19, where it is indicated and should not be delayed because of fetal concerns. For safety of the fetus abdominal shield can be used as normal protocol $^{90-92}$.

\section{Treatment:}

\section{Oxygen therapy:}

- Oxygen therapy should be started early to maintain $\mathrm{O}_{2}$ saturation $>95 \%$ and $/$ or $\mathrm{PO}_{2} \geq 70 \mathrm{mmHg}$. If needed high flow nasal canula should be started. If $\mathrm{O}_{2}$ saturation cannot be maintained by high flow nasal $\mathrm{O}_{2}$ therapy, non-invasive ventilation can be used. Even then if saturation is not increased patient should be kept in mechanical ventilator. In case of failure to improve the saturation extracorporeal membrane oxygenation can be used as last resort. Though success story is not high, miracle may happen if can be instituted earlier ${ }^{93}$.

\section{Drug:}

All drugs and other therapies which are using in the management of COVID-19 patients are investigational. No confirm therapeutic drug has been established yet.

- Because of risk of bacterial superinfection empiric antimicrobial therapy can be considered. Other bacterial infection, viral infection should be screened to identify any coinfection.

- Remdesivir: The antiviral drug remdesivir gained emergency use authorization (EUA) from the FDA on May 1, 2020, based on preliminary data showing a faster time to recovery of hospitalized patients with severe disease ${ }^{94-96}$.

- Ivermectin: In a hospital of Florida use of Ivermectin in COVID-19 patients shows that mortality rate was lower $(15 \%)$ in comparison to patients who did not receive it $(25.2 \%) \mathrm{p}=0.03$. Mortality rate was also lower in patient with severe pulmonary disease treated with ivermectin $(38.8 \%$ vs $80.7 \%, p=0.001)$, though there was no significant difference in successful extubation rate ${ }^{97}$.

- Hydroxychloroquine: Regarding hydroxychloroquine a very recent large study (SOLIDARITY trial) on 3016 COVID-19 cases shows no benefit, rather increased frequency of ventricular arrythmia in comparison to control group ${ }^{86}$.

Because of these findings, the WHO paused the hydroxychloroquine arm of the SOLIDARITY Trial. The FDA issued a safety alert for hydroxychloroquine or chloroquine use in COVID19 on April 24, $2020^{98}$. But on June $3^{\text {rd }}$ again started trial and IDSA recommended it's use in the hospital setting only for clinical trial ${ }^{87}$. On June 15, 2020 the FDA revoked the emergency use authorization for hydroxychloroquine to be used for treating certain hospitalized patients with COVID-19 when clinical trail is not available or feasible 99 .

- Lopinavir/ritonavir: The IDSA panel recommends the combination of lopinavir/ritonavir only in the context of a clinical trial ${ }^{87}$. Though mortality rate at 28 days is slightly lower in comparison to standard care $(19.2 \%$ vs $25 \%)$ but is not significant statistically 100 .

- Corticosteroid: Routine use of corticosteroid in viral pneumonia has been associated with increased morbidity, so, it is not recommended ${ }^{101,102}$. IDSA also against the use of corticosteroid in COVID pneumonia but recommended to use in acute respiratory distress syndrome (ARDS) due to COVID-19 in the context of clinical trial ${ }^{87}$. Judicial use of steroid for fetal lung maturity is recommended but urgent intervention of birth should not be delayed for their use ${ }^{103}$. RECOVERY trial of oxford university shows that dexamethasone at a dose of 6 mg per day orally or injectable reduced deaths by one-third in ventilated patients (rate ratio 0.65 [95\% confidence interval 0.48 to 0.88 ]; $p=0.0003$ ) and by one fifth in other patients receiving oxygen only ( 0.80 [0.67 to 0.96$] ; p=0.0021$ ). There was no benefit among those patients who did not require respiratory support (1.22 [0.86 to $1.75 ; \mathrm{p}=0.14$ ) (Unpublished, Medscape newsletter $)^{104}$. 
- Interleukin 6 inhibitors: Sarilumab and Tocilizumab are drugs can prevent cytokin storm in critical patients and reduce mortality ${ }^{105-108}$.

- LMWH: All pregnant women with COVID-19 infection should receive low molecular weight heparin (LMWH), unless birth is expected within 12 hours or other contraindication exists ${ }^{109}$. Pregnancy is a hypercoagulable state and evidence suggest that patients admitted with COVID-19 infections are also hypercoagulable with a risk of thromboembolism 109,110. Moreover, reduced mobility resulting from self-isolation likely to increase the risk.

\section{Fluid and Convalescent plasma:}

- Intravenous (IV) fluid: IV fluid should be used conservatively to keep the lung dry unless there is cardiovascular instability. In moderate to severe ARDS cases hourly intake output chart should be monitored $^{111}$.

- Convalescent plasma therapy: Treatment with the antibody rich plasma of recovered COVID-19 patient is controversial and is using in some places. The data of most recent controlled study did not show any statistically significant improvement when compared convalescent plasma therapy to patients with severe or life-threatening COVID-19 with standard treatment alone ${ }^{112}$. Though a nonrandomized study with historical control show that convalescent plasma therapy improved survival in non-intubated patient $(\mathrm{p}=0.015)$ but not in intubated patient $(p=0.752)^{113}$ IDSA recommends COVID-19 convalescent plasma in the context of a clinical trial ${ }^{87}$.

- Prone positioning: Prone positioning can be considered in severe acute respiratory distress syndrome, rotating 8 hourly. If it is not feasible due to distended abdomen in third trimester, any lateral position preferably left should be adopted. Direct supine position should be avoided.

In case of rise of temperature emphasis should be given to control sepsis. If septic shock is suspected prompt targeted management should be started.

\section{How to deliver the baby?}

Timing of delivery:

Timing of delivery or termination of pregnancy and mode of delivery should be based on gestational age, maternal condition, foetal condition and maternal wishes. Counselling to patient and families is essential regarding condition of the patient and baby, management strategy, management wishes of the patient and prognosis of management. Patient must be stabilized before intervention for birth if she is not in labour.

\section{Delivery:}

\section{Intra-natal care:}

Number of staff members entering the room should be minimum. Only one asymptomatic birth partner can be allowed. Health care provider must wear full PPE before attending the patient. Sometimes cases may be so emergency that Donning of PPE is time consuming, which may impact on the decision to delivery interval. But it must be done by informing the woman and her family about this possible delay. Mode of delivery is determined by patient preference and obstetrical indications. COVID19 itself is not an indication of caesarean section (C/S). Decision should be taken by individualized assessment after proper discussion with the patient to cut short the length of $2^{\text {nd }}$ stage of labour particularly for women who are becoming exhausted and hypoxic. If patient has respiratory distress, process of labour imposes added stress on that situation. Vaginal delivery can be allowed but during bearing down effort forceful exhalation may significantly reduce the effectiveness of a mask in preventing the spread of the virus by respiratory droplet. Moreover, wearing mask might interfere bearing down effect. Considering these things to accelerate birth process caesarean section can be done. A number of studies shown the mode of delivery in their series was caesarean section ${ }^{14-17}$. There is no contraindication of vaginal delivery in fear of infection contraction, as no virus was found in vaginal fluid in different studies ${ }^{23,33,34}$. But the most recent report shows positive RT-PCR test of vaginal swab of two women, though infectivity of the virus was not tested. Both babies' nasopharyngeal swab was positive for RT-PCR, but mode of delivery was not mentioned in this short report. (Medscape July 10, 2020). To avoid the risk of infection via feces using birth pool in the hospital should be avoided.

Maternal condition should be monitored closely as standard labour management protocol with the addition of hourly oxygen saturations, aiming to keep oxygen saturation more than $94 \%$ and titrating oxygen therapy accordingly. Use of Entonox is not universal all over the world but in UK this is standard. It can be used with a single microbiological filter. Use of Entonox is not an aerosol-generating procedure ${ }^{112}$. Though in one report it is not recommended to use nitrous oxide as it may 
involve the risk of aerosolization and involves respiratory contamination ${ }^{114}$.

As fetal compromise is more according to Chen et al, constant fetal monitoring is advocated. LMWH should be omitted before delivery or operation and can be reinstituted as soon as possible after birth if there is no postpartum haemorrhage or regional anaesthesia has not been used. Where regional anaesthesia has been used LMWH can be re-administered 4 hours after spinal anaesthesia or removal of epidural catheter ${ }^{109}$. Caeserean section should be done in a negative pressure room. It is safe to avoid cautery. In earlier series of China caesarean section rate was high 26/30 (81.25\%) due to foetal distress, vaginal bleeding, premature rupture membrane, gestational hypertension, preeclampsia and other medical disorders ${ }^{14-17}$. Most of the cases were done to cut short the duration of labour. But subsequently other two reports of China ${ }^{12,69}$ shows C/ $\mathrm{S} 38 / 62(61 \%)$, and report of large series of UK shows $\mathrm{C} /$ S 63/243 (16\%) solely due to effect of COVID-19 like distress of the mother. So, COVID-19 itself is not an indication of $\mathrm{C} / \mathrm{S}$ so long mother develops any complication of the disease. Both regional (Spinal, epidural) and general anesthesia (G/A) can be used. But better to avoid $\mathrm{G} / \mathrm{A}$ if possible.

Elective caesarean section: In some cases where date of elective caesarean section overlapped her isolation period, schedule can be changed after proper assessment of the patient to avoid the risk of transmission to other women, healthcare providers and postnatally to her baby. If birth cannot be delayed for safety of the baby then it will be done maintaining the protocol of COVID-19 management.

Planned induction of labour: In the same way of elective $\mathrm{C} / \mathrm{S}$ if for any reason it is not possible to reschedule the date till recovery of the patient, she should be admitted into an isolation room and there she should be cared as COVID-19 management protocol.

\section{Timing of discharge of the patient:}

The decision to discharge of a patient from the hospital should be based on the clinical condition of the patient herself and the baby. Issue of maternal discharge should be discussed with paediatrician/neonatologist to determine timing of infant discharge. If both baby and patient's condition are good, all vaginal delivery can be discharged on $1^{\text {st }}$ postpartum day or even on the same day if seems to be safe. All caesarean section can be discharged on $2^{\text {nd }}$ postoperative day. First postoperative day also may be considered assessing and meeting safety milestones. Patients with risk factors like hypertension and diabetes can be discharged earlier if blood pressure and blood sugar is under control. She should be advised regarding checking blood pressure and blood sugar at home and taking necessary teleconsultation or in-person consultation if needed ${ }^{115}$.

Discharge of the patients of critical care management in ICU will depend on ICU management protocol of COVID-19.

\section{Post-natal Care:}

As this is a new virus, there is limited evidence about special caring for women with coronavirus infection when they have just given birth. Postnatal care should be continued according to standard protocol. At the time of discharge from hospital women should be prescribed LMWH at least for 10 days and longer course should be offered where indicated ${ }^{109}$. After discharge both face-to face and remote postnatal follow up should be done according to the woman and babies need. Patient should be advised to test for recovery, if applicable.

\section{Neonatal care:}

Transplacental viral transmission from mother to newborn has not been clearly demonstrated in the literature. So, delayed cord clamping can continue per normal center practices. Till today among large number of $3^{\text {rd }}$ trimester babies there is no strong evidence of vertical transmission ${ }^{14}{ }^{17,29}$. In-spite of this negative findings RT-PCR of nasopharyngeal swab of all babies of COVID-19 and suspected or probable patients should be done. Most of the authors kept the baby isolated from mother for 14 days. However, this may have potential negative effects on feeding and bonding.

Few babies had different symptoms which were not directly to COVID-19 infection rather it was for maternal obstetric and COVID-19 related hypoxia and prematurity of the baby. Some RT-PCR positive babies X-ray chest showed radiographic images whose mothers amniotic fluid, placental membrane vaginal fluid were negative for RT-

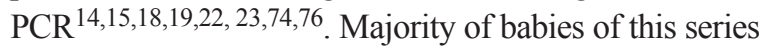
did not show any pulmonary symptoms. Only one baby died of multiorgan failure who needed NICU support. Two babies had atrial septal defect without significant symptom. 
Other babies had no significant problem as well. In general birth asphyxia, transient respiratory distress, pneumonia, fever, shortness of breath, ARDS, vomiting, edema, skin rash, milk rejection and gastrointestinal bleeding were also reported by authors ${ }^{14,22,74,76}$.Intrauterine foetal distress, maternal distress and prematurity are the most causal factors. So, neonates should be managed according to their need. If baby is quite normal no need of care in the neonatal units.

In case of intensive care and respiratory support, admission to a single-patient room with negative room pressure is ideal. If multiple newborns with exposure to COVID-19 kept in one room, they should be kept at least six feet apart. and/or kept in temperature-controlled chamber.

Care providers should wear full PPE, gowns, gloves, N95 respiratory mask, goggles or an air-purifying respirator that protects the eyes to treat infants who require supplemental oxygen at more than $2 \mathrm{~L} / \mathrm{m}$, continuous positive airway pressure, or mechanical ventilation.

\section{Feeding of newborn:}

There is no evidence showing that the virus can be carried or passed in breastmilk ${ }^{15,18,23}$. So, there is no contraindication of breast feeding. The well-recognized benefits of breastfeeding and the protection it offers to babies outweigh any potential risks of transmission of coronavirus through breastmilk. Provided baby is well and does not require care in the neonatal unit, mother can stay together after giving birth, so skin-to-skin and breastfeeding can be initiated and supported if mother choose.

UNICEF, CDC and $\mathrm{WHO}^{116-118}$ recommended to continue breastfeeding their baby with maintaining hygiene. They advised to

- Wear a mask when feeding their baby

- Wash hands before and after touching the baby and

- Routinely clean and disinfect surfaces.

The main risk of breastfeeding is close contact between mother and baby. So, Wang et al recommended isolation of the baby from mother for 14 days and did not recommend breast feeding ${ }^{119}$.

A discussion about the risks and benefits of breastfeeding should take place between patient, family and maternity team. When anyone else does not want to feed her baby directly in fear of contracting infection or patient is seriously ill due to COVID-19 or when other complications prevent her from caring and breastfeeding her baby, she should encouraged to use expressed milk for baby maintaining proper hygiene ${ }^{116-118}$. In case of critically ill patient for whom it is not possible to collect milk, alternate feeding is advised.

\section{Newborn discharge:}

Newborns born to mothers with COVID-19 should be discharged per the hospital's own policy normal criteria. Early discharge is not necessary.

Babies of asymptomatic positive mother should follow same precaution. Asymptomatic positive for SARS-CoV2 neonates should undergo frequent outpatient followup either face to face or via telemedicine for 14 days after birth. Infection-control precautions should be observed at home and in the outpatient office. Test for recovery should be advised for RT-PCR positive babies.

Infants who test negative for SARS-CoV-2 are likely to be discharged to the care of mother with infectionprevention instructions. Following hospital discharge, COVID-19 mothers should maintain safety by distancing, hand washing and wearing mask at least 10 days has passed since the onset of symptoms.

\section{Conclusion:}

COVID-19 pandemic is a global disease which killed more than 5.8 lac people worldwide. This new viral outbreak is affecting more and more countries and rapidly increasing the number of cases and death. Much is unknown about the virus, it's diverging pathology, mode of transmission, efficacy of antiviral drugs and preventive vaccine.

At present no data is available to observe the outcome of SARS-CoV-2 infection at $1^{\text {st }}$ and $2^{\text {nd }}$ trimester of pregnancy and limited data are available on pregnant women of $3^{\text {rd }}$ trimester with COVID-19. Based on this and lessons from SARS, MERS and other respiratory infections, it is observed that pregnant women could have a severe clinical course though less severe in COVID-19 than SARS and MERS. Based on released data from different countries, recommendations were made by WHO, UNICEF, UNFPA, CDC, FIGO, RCOG and other bodies for pregnancy-care of COVID-19 patients. 
About vertical transmission it is still not conclusive that it is transmitted to the fetus and causes any adverse effect. Though in two cases SARS -CoV-2 RNA found in the fetal side of the placenta and nasopharyngeal swab of babies who were isolated from mother, there was no developmental defect as their mothers exposed to infection after their complete growth and development. Italian researchers reported on the basis of positive RTPCR and antibody tests from multiple sites of mothers and babies that vertical transmission is possible and it can't be dismissed. If mother is infected during organogenesis, it is not sure what will be the outcome of the fetus. It may turn out as miscarriage or birth defect. We have to wait for few more months till delivery of those babies whose mothers are infected by SARS-Cov-2 at their $1^{\text {st }}$ trimester.

Finally, every community must be vigilant about the spread of the disease and should be able to implement appropriate measures to control and manage the outbreak untill any effective vaccine (s) is (are) made available.

\section{References:}

1. Rasmussen SA, Smulian JC, Lednicky JA, Wen TS, Jamieson DJ. Coronavirus Disease 2019 (COVID-19) and pregnancy: what obstetricians need to know. Am J Obstet Gynecol. 2020;222(5):415-426.

2. Zhongguo Dang Dai Er Ke Za Zhi. Zhongguo Dang Dai Er Ke Za Zhi. Zhongguo Dang Dai Er Ke Za Zhi. Working Group for the Prevention and Control of Neonatal 2019nCoV Infection in the Perinatal Period of the Editorial Committee of Chinese Journal of Contemporary Pediatrics. [Perinatal and neonatal management plan for prevention and control of 2019 novel coronavirus infection (1st Edition)]. 2020;22:87-90.

3. Schwartz DA, Graham AL. Potential maternal and infant outcomes from (Wuhan) Coronavirus 2019-nCoV infecting pregnant women: lessons from SARS, MERS, and other human coronavirus infections. Viruses. 2020;12(2):194.

4. Ma K, Chen T, Han MF, Guo W, Ning Q. [Management and clinical thinking of Coronavirus Disease 2019]. Zhonghua Gan Zang Bing Za Zhi. 2020;28:E002.

5. World Health Organization. Coronavirus disease (COVID19) outbreak; n.d. [accessed 2020 Mar 4]. https:// www.who.int/emergencies/diseases/novel-coronavirus-2019.

6. Gorbalenya AE. Severe acute respiratory syndrome-related coronavirus - the species and its viruses, a statement of the Coronavirus Study Group. BioRxiv 2020:2020.02.07.937862.

7. The ANZIC Influenza Investigators and Australasian Maternity Outcomes Surveillace System. Critical illness due to $2009 \mathrm{~A} / \mathrm{H} 1 \mathrm{~N} 1$ influenza in pregnant and postpartum women: population based cohort study. BMJ 2010;340:c1279.
8. Jamieson DJ, Honein MA, Rasmussen SA, et al. H1N1 2009 influenza virus infection during pregnancy in the USA. Lancet 2009;374(9688):451-8.

9. Louie JK, Acosta M, Jamieson DJ, et al. Severe 2009 H1N1 influenza in pregnant and postpartum women in California. N Engl J Med 2010;362(1):27-35.

10. Siston AM, Rasmussen SA, Honein MA, et al. Pandemic 2009 influenza $\mathrm{A}(\mathrm{H} 1 \mathrm{~N} 1)$ virus illness among pregnant women in the United States. JAMA 2010;303(15):1517-25.

11. Wong SF, Chow KM, Leung TN, et al. Pregnancy and perinatal outcomes of women with severe acute respiratory syndrome. American journal of obstetrics and gynecology 2004;191(1):292-7.

12. Mullins E, Evans D, Viner RM, et al. Coronavirus in pregnancy and delivery: rapid review. Ultrasound Obstet Gynecol 2020;55:586-592.

13. Alfaraj SH, Al-Tawfiq JA, Memish ZA. Middle East Respiratory Syndrome Coronavirus (MERS-CoV) infection during pregnancy: Report of two cases \& review of the literature. Journal of microbiology, immunology, and infection Wei mian yu gan ran za zhi 2019;52(3):501-03.

14. Zhu H, Wang L, Fang C, Peng S, Zhang L, Chang G, et al. Clinical analysis of 10 neonates born to mothers with 2019nCoV pneumonia. Trans1 Pediatr. 2020;9:51-60.

15. Chen H, Guo J,Wang C, Luo F, Yu X, ZhangW, et al. Clinical characteristics and intrauterine vertical transmission potential of COVID-19 infection in nine pregnant women: a retrospective review of medical records. Lancet. (2020) 395:809-15.

16. Lei D, Wang C, Li C, Zhou Z, Liu S, Rong Z. Clinical characteristics of COVID-19 in pregnancy: analysis of nine cases. Chin J Perinat Med. (2020) 23. doi: 10.3760/ cma.j.cn113903-20200216-00117

17. Yu N, Li W, Kang Q, Xiong Z, Wang S, Lin X, et al. Clinical features and obstetric and neonatal outcomes of pregnant patients with COVID-19 in Wuhan, China: a retrospective, single-centre, descriptive study. Lancet Infect Dis. 2020; 20:559-64.

18. Wang S, Guo L, Chen L, Liu W, Cao Y, Zhang Y, et al. A case report of neonatal COVID-19 infection in China. Clin Infect Dis. 2020; 12:ciaa225. doi: 10.1093/cid/ciaa225

19. Zeng L, Xia S, Yuan W, Yan K, Xiao F, Shao J, et al. Neonatal early-onset infection with SARS-CoV-2 in 33 neonates born to mothers with COVID-19 in Wuhan, China. JAMA Pediatr. (2020). doi: 10.1001/ jamapediatrics.2020.0878. [Epub ahead of print].

20. Li M, Xu M, Zhan W, Han T, Zhang G, Lu Y. [Report of the first cases of mother and infant infections with 2019 novel coronavirus in Xinyang City Henan Province]. Chin J Infect Dis. (2020) 38:E007. doi: 10.3760/cma.j.issn.10006680.2020 .0007

21. Zamaniyan M, Ebadi A, Aghajanpoor S, Rahmani Z, Haghshenas M, Azizi S,Preterm delivery in pregnant woman 
with critical COVID 19 pneumonia and vertical transmission. First published:17 April 2020 https://doi.org/ 10.1002/pd.5713

22. Zeng H, Xu C, Fan J, Tang Y, Deng Q, Zhang W, et al. Antibodies in infants born to mothers with COVID-19 Pneumonia. JAMA. (2020) 323:1848-9.

23. Dong L, Tian J, He S, Zhu C, Wang J, Liu C, et al. Possible vertical transmission of SARS-CoV-2 from an infected mother to her newborn. JAMA. (2020) 323:1846-8.

24. Kohler PF, Farr RS. Elevation of cord over maternal IgG immunoglobulin: evidence for an active placental IgG transport. Nature. 1966;210(5040):1070-1071.

25. Woo PC, Lau SK, Wong BH, et al. . Detection of specific antibodies to severe acute respiratory syndrome (SARS) coronavirus nucleocapsid protein for serodiagnosis of SARS coronavirus pneumonia. J Clin Microbiol. 2004;42(5):23062309.

26. Ng WF, Wong SF, Lam A, et al. . The placentas of patients with severe acute respiratory syndrome: a pathophysiological evaluation. Pathology. 2006;38(3):210-218.

27. Christina A. Penfield, MD, MPH, Sara G. Brubaker, MD, MS, Meghana A. Limaye, MD, Jennifer Lighter, MD, Adam J. Ratner, MD, MPH, Kristen M. Thomas, MD, Jessica Meyer, MD, Ashley S. Roman, MD, MPH. Detection of SARS-COV-2 in Placental and Fetal Membrane Samples. American Journal of Obstetrics \& Gynecology MFM. PII:S2589-9333(20)30076-8.

28. Patanè L, Morotti D, Giunta MR, Sigismondi C, Piccoli MG, Frigerio L, Mangili G, Arosio M, Cornolti G, Vertical transmission of COVID-19: SARS-CoV-2 RNA on the fetal side of the placenta in pregnancies with COVID-19 positive mothers and neonates at birth, American Journal of Obstetrics \& Gynecology MFM (2020), doi: https://doi.org/ 10.1016/j.ajogmf.2020.100145.

29. Yan J, Guo J, Fan C, et al. Coronavirus disease 2019 in pregnant women: a report based on 116 cases. Am J Obstet Gynecol 2020;XX:x.exex.ex.

30. Hillary Hosier1*, Shelli Farhadian2 *, Raffaella A. Morotti3 , Uma Deshmukh1, Alice Lu-Culligan4, Katherine H. Campbell1, et al. SARS-CoV-2 infection of the placenta. medRxiv preprint doi: https://doi.org/10.1101/ 2020.04.30.20083907.

31. Transmission electron microscopic image of an isolate from the first U.S. case of COVID-19, formerly known as 2019-nCoV. . Centers for Disease Control and Prevention 2020. (Accessed April 16, 2020, at https://phil.cdc.gov/ Details.aspx?pid=23336.)

32. Baud D et al. Second-trimester miscarriage in a pregnant woman with SARS-CoV-2 infection. JAMA 2020 Apr 30; [e-pub]. (https://doi.org/10.1001/jama.2020.7233)

33. Qiu L, Liu X, Xiao M, Xie J, Cao W, Liu Z, Morse A, Xie Y, $\mathrm{Li}$ T, Zhu L. SARS-CoV-2 is nt detectable in the vaginal fluid of women with severe COVID-19 infection. Clin Infect
Dis. 2020 Apr 2:ciaa375. doi: 10.1093/cid/ciaa375. Epub ahead of print. PMID: 32241022; PMCID: PMC7184332.

34. Cui P, Chen Z, Wang T, et al. Clinical features and sexual transmission potential of SARS-CoV-2 infected female patients: a descriptive study in Wuhan, China medRxiv. 2020:2020.2002.2026.20028225.

35. Diangeng Li, PhD; Meiling Jin, MD; Pengtao Bao, PhD et al. Clinical Characteristics and Results of Semen Tests Among Men With Coronavirus Disease 2019. JAMA Network Open. 2020;3(5):e208292.

36. Wang, Z. \& Xu, X. scRNA-seq Profiling of Human Testes Reveals the Presence of the ACE2 Receptor, A Target for SARS-CoV-2 Infection in Spermatogonia, Leydig and Sertoli Cells. Cells 2020; 9: 920.

37. Zhou L, Niu Z, Jiang Xi, Zhang Z, Zheng Y, Wang Z, et al. Systemic analysis of tissue cells potentially vulnerable to SARS-CoV-2 infection by the protein-proofed single-cell RNA profiling of ACE2, TMPRSS2 and Furin proteases ISCIENCE-D-20-00768. Available at SSRN: https:// ssrn.com/ abstract= 3589839 or http://dx.doi.org/10.2139/ ssrn. 3589839

38. Guan WJ, Ni ZY, Hu Y, et al. Clinical characteristics of 2019 novel coronavirus infection in China. N Engl J Med. 2020;382(18):1708-1720.

39. Dan H, Maureen G, Richard B, et al. Quantitative mRNA expression proфling of ACE 2, a novel homologue of angiotensin converting enzyme. FEBS.Lett. 2020;532(12):107-110.

40. Letko M, Marzi A, Munster V. Functional assessment of cell entry and receptor usage for SARS-CoV-2 and other lineage B betacoronaviruses. Nat Microbiol. 2020;5(4):562569.

41. Wang D, Hu B, Hu C, et al. Clinical characteristics of 138 hospitalized patients With 2019 novel coronavirus- infected pneumonia in Wuhan, China. JAMA. 2020;323(11):10611069.

42. Ling Lin, Lianfeng Lu, Wei Cao \& Taisheng Li. Hypothesis for potential pathogenesis of SARS-CoV-2 infection-a review of immune changes in patients with viral pneumonia. Emerg Microbes Infect. 2020;9(1): 727-732.

43. Siston AM, Rasmussen SA, Honein MA, Fry AM, Seib K, Callaghan WM, Louie J, Doyle TJ, Crockett M, Lynfield R, Moore Z, Wiedeman C, Anand M, Tabony L, Nielsen $\mathrm{CF}$, et al.; PandemicH1N1 Influenza in Pregnancy WorkingGroup. Pandemic 2009 influenza A(H1N1) virus illness among pregnant women in the United States. JAMA. 2010; 303: 1517-1525.

44. Zhang Y, Xiao M, Zhang S et al. Coagulopathy and antiphospholipid antibodies in patients with Covid-19. N Engl J Med. 2020;382(17):e38.

45. Facing COVID-19 in the ICU: vascular dysfunction, thrombosis, and dysregulated infammation Daniel E. 
Leisman1, Cliford S. Deutschman2 and Matthieu L Intensive Care Med. (C) 2020 Springer-Verlag GmbH Germany, part of Springer Nature https://doi.org/ 10.1007/ s00134-02006059-6 egrand $3 *$

46. Zhou F, Yu T, Du R, Fan G, Liu Y, Liu Z, et al. Clinical course and risk factors for mortality of adult inpatients with COVID-19 in Wuhan, China: a retrospective cohort study. Lancet. 2020 Mar 11. [Medline].

47. Wu Z, McGoogan JM. Characteristics of and Important Lessons From the Coronavirus Disease 2019 (COVID-19) Outbreak in China: Summary of a Report of 72/ 314 Cases From the Chinese Center for Disease Control and Prevention. JAMA. 2020 Feb 24. [Medline].

48. CDC COVID-19 Response Team. Preliminary Estimates of the Prevalence of Selected Underlying Health Conditions Among Patients with Coronavirus Disease 2019 - United States, February 12-March 28, 2020. Morbidity and Mortality Weekly Report (MMWR). Available at https:// www.cdc.gov/mmwr/volumes/69/wr/mm6913e2.htm. March 31, 2020; Accessed: April 2, 2020.

49. CDC. Coronavirus Disease 2019 (COVID-19): People who are at higher risk for severe illness. Centers for Disease Control and Prevention. Available at https://www.cdc.gov/ coronavirus/2019-ncov/need-extra-precautions/people-athigher-risk.html. Accessed: April 2, 2020.

50. Babadaei MMM, Hasan A, BloukhSA, Edis Z, Sharifi M, Kachooei E \& Falahati M(2020): The expression level of angiotensin-converting enzyme 2 determine the severity of COVID-19: lung and heart tissue as targets, Journal of Biomolecular Structure and Dynamics, DOI: 10.1080/ 07391102.2020 .1767211

To link to this article: https://doi.org/10.1080/ 07391102.2020 .1767211

51. Fang L, Karakiulakis G, Roth M. Are patients with hypertension and diabetes mellitus at increased risk for COVID-19 infection? (correspondence). Lancet Respir Med. 2020 Mar 11.

52. Clerkin KJ, Fried JA, Raikhelkar J, Sayer G, Griffin JM, Masoumi A, et al. Coronavirus Disease 2019 (COVID-19) and Cardiovascular Disease. Circulation. 2020 Mar 21.

53. Kuba K, Imai Y, Rao S, Gao H, Guo F, Guan B, et al. A crucial role of angiotensin converting enzyme 2 (ACE2) in SARS coronavirus-induced lung injury. Nat Med. 2005 Aug. 11 (8):875-9.

54. CDC. 2019 Novel Coronavirus, Wuhan, China: Symptoms. CDC. Available at https://www.cdc.gov/coronavirus/2019ncov/about/symptoms.html. January 26, 2020; Accessed: January 27, 2020

55. CDC. Symptoms of Coronavirus. CDC. Available at https:/ /www.cdc.gov/coronavirus/2019-ncov/symptoms-testing/ symptoms.html. March 20, 2020; Accessed: April 28, 2020.
56. Docherty AB, Harrison EM, Green CA, et al. Features of 16,749 hospitalised UK patients with COVID-19 using the ISARIC WHO Clinical Characterisation Protocol. medRxiv 2020:2020.04.23.20076042. doi:10.1101/2020.04.23. 20076042

57. Berkowitz K, LaSala A. Risk factors associated with the increasing prevalence of pneumonia during pregnancy. Am J Obstetr Gynecol. 1990;163:981-5. doi:10.1016/00029378(90)91109-p.

58. Schwartz DA, Graham AL. Potential maternal and infant outcomes from (Wuhan) Coronavirus 2019-nCoV infecting pregnant women: lessons from SARS, MERS, and other human coronavirus infections. Viruses. 2020;12(2):194.

59. Robertson CA, Lowther SA, Birch T, Tan C, Sorhage F, Stockman L, McDonald C, Lingappa JR, Bresnitz E. SARS and Pregnancy: A Case Report. Emerg Infect Dis 2004; 10: 345-348.

60. Li AM, Ng PC. Severe acute respiratory syndrome (SARS) in neonates and children. Arch Dis Child Fetal Neonatal Ed 2005; 90: 461-465.

61. Lam CM, Wong F, Leung N, Chow M. A case-controlled study comparing clinical course and outcomes of pregnant and non-pregnant women with severe acute respiratory syndrome. BJOG; 2004; 111: 771-774.

62. Shek CC, Ng PC, Fung GPG, Cheng FWT, Chan PKS, Peiris MJS, Lee KH, Wong SF, Cheung HM, Li AM, Hon EK, Yeung CK, Chow CB, Tam JS, ChiuMC, Fok TF. Infants Born to Mothers With Severe Acute Respiratory Syndrome. Pediatrics 2020; 112: e254.

63. Alserehi H, Wali G, Alshukairi A, Alraddadi B. Impact of Middle East Respiratory Syndrome coronavirus (MERS$\mathrm{CoV}$ ) on pregnancy and perinatal outcome. BMC Infect Dis 2016; 16: $1-4$.

64. Jeong SY, Sung SI, Sung J, Ahn SY, Kang E, Chang YS, Park WS, Kim JH.MERS-CoV Infection in a Pregnant Woman in Korea. J Korean Med Sci 2017; 3: 5-8.

65. Assiri A, Abedi G, Malak M, Abdulaziz B, Gerber S, Watson JT. Pregnancy: A Report of 5 Cases From Saudi Arabia. Clin Infect Dis 2016; 63: 951-953.

66. Park MH, Kim HR, Choi DH, Sung JH, Kim JH. Emergency cesarean section in an epidemic of the middle east respiratory syndrome. Korean J Anesthesiol 2016; 69:287291.

67. Malik A, Medhat K, Masry E, Ravi M, Sayed F. Middle East Respiratory Syndrome Coronavirus during Pregnancy, Abu Dhabi, United Arab Emirates, 2013. Emerg Infect Dis 2016; 22: 515-517.

68. Payne D, Ibrahim I, Sultan A. Stillbirth During Infection With Middle East Respiratory Syndrome Coronavirus. J Infect Dis 2014; 209: 1870-1872.

69. Chen L, Li Q, Zheng D, Jiang H, Wei Y, Zou L, et al. Clinical characteristics of pregnant women with covid-19 
in Wuhan, China. N Engl J Med. (2020). doi: 10.1056/ NEJMc2009226. [Epub ahead of print]

70. Knight M, Bunch K, Vousden N, Edward Morris E et al. Characteristics and outcomes of pregnant women hospitalized with confirmed SARS-CoV-2 infection in the UK: a national cohort study using the UK Obstetric Surveillance System (UKOSS) doi: https://doi.org/10.1101/ 2020.05.08.20089268

71. Guan W, Ni Z, Hu Y, et al. Clinical characteristics of coronavirus disease 2019 in China. N Engl J Med. 2020;382:1708-1720.

72. Khunti K, Singh AK, Pareek M, et al. Is ethnicity linked to incidence or outcomes of covid-19? BMJ 57 2020;369:m1548. doi: 10.1136/bmj.m1548.

73. Putra M, Kesavan M, Brackney K, et al. Forecasting the impact of coronavirus disease during delivery hospitalization: an aid for resource utilization. Am J Obstet Gynecol MFM 2020; 2589-9333. https://doi.org/10.1016/ j.ajogmf.2020.100127

74. Li N, Han L, Peng M, Lv Y, Ouyang Y, Liu K, Yue L, Li Q, Sun G, Chen L, Yang L. Maternal and neonatal outcomes of pregnant women with COVID-19 pneumonia: a casecontrol study. Clin Infect Dis. 2020 Mar 30. pii: ciaa352.

75. Kamali Aghdam M, Jafari N, Eftekhari K. Novel coronavirus in a 15-day-old neonate with clinical signs of sepsis, a case report. Infect Dis (Lond). 2020 Apr 1:1-3.

76. Alonso Díaz C, López Maestro M, Moral Pumarega MT, Flores Antón B, Pallás Alonso C. First case of neonatal infection due to SARS-CoV-2 in Spain. An Pediatr (Barc). 2020 Mar 31. pii: S1695-4033(20)30130-2.

77. Kirkham C, Hrris S, Grzybowski S. Evidence-based prenatal care:part 1. General prenatal care and counseling issues. Am Fam Physician. 2005;71(7):1307-22.

78. Dowswell T, Carroli G, Duley L, Gates S, Gulmezoglu AM et al.Alternative versus standard packages of antenatal care for low-risk pregnancy. Cochrane Database Syst Rev. 2015(7):CD000934.

79. World Health Organization, WHO recommendations on antenatal care for a positive pregnancy experience. 2016, World Health Organization: Geneva.

80. World Health Organization. WHO recommendation on antenatal care contact schedules. 2018 [cited 20207 April]; Available from: https:/extranet.who.int/rhl/topics/ improving-health-system-performance/whorecommendation-antenatal-care-contact-schedules.

81. Antenatal Visits during COVID-19 Pandemic. Perinatal Services BC. Provincial Health Services Authority.

82. FIGO (International Federation Gynecology and Obstetrics) www.figo.or

83. Lapinsky SE. Management of acute respiratory failure in pregnancy. Semin Respir Crit Care Med 2017;38:201-7.

84. Centers for Disease Control and Prevention. Interim infection prevention and control recommendations for patients with confirmed 2019 novel coronavirus (2019$\mathrm{nCoV}$ ) or patients under investigation for 2019-nCoV in healthcare settings. Centers for Disease Control and Prevention. Updated Feb. 3, 2020. Available at: https:// www.cdc.gov/coronavirus/2019-nCoV/hcp/ infectioncontrol.html. Accessed February 11, 2020.

85. Centers for Disease Control and Prevention. Interim guidance for implementing home care of people not requiring hospitalization for 2019 novel coronavirus (2019nCoV). Updated Jan. 31, 2020. Available at: https:// www.cdc.gov/ coronavirus/2019-ncov/hcp/guidancehomecare. html?CDC_AA_refVal $1 / 4 \mathrm{https} \% 3 \mathrm{~A} \% 2 \mathrm{~F} \%$ 2Fwww.cdc.gov\%2Fcoronavirus\%2F2019 ncov\%2 Fguidance-home-care.html. Accessed February 11, 2020.

86. Mehra MR, Desai SS, Ruschitzka F, Patel AN. Hydroxychloroquine or chloroquine with or without a macrolide for treatment of COVID-19: a multinational registry analysis. Lancet 2020; published online May 22. https://doi.org/10.1016/S0140-6736(20)31180-6.

87. [Guideline] Bhimraj A, Morgan RL, Shumaker AH, et al. Infectious Diseases Society of America Guidelines on the Treatment and Management of Patients with COVID-19. IDSA. Available at https://www.idsociety.org/practiceguideline/covid-19-guideline-treatment-and-management/ . April 13, 2020; Accessed: April 13, 202

88. Yang X, Yu Y, Xu J, Shu H, Xia J, Liu H et al. Clinical course and outcomes of critically ill patients with SARS-CoV-2 pneumonia in Wuhan, China: a single-centered, retrospective, observational study. Lancet Respir Med. 2020;2600(20)30079-5.

89. Wu Z, McGoogan JM. Characteristics of and important lessons from the coronavirus disease 2019 (COVID-19) outbreak in China: summary of a report of 72314 cases from the Chinese Center for Disease Control and Prevention. JAMA. 2020. Epub 2020/02/25. doi: 10.1001/ jama.2020.2648. PubMed PMID: 32091533

90. Li X, Xia L. Coronavirus Disease 2019 (COVID-19): Role of Chest CT in Diagnosis and Management. AJR Am J Roentgenol 2020(4):1-7.

91. Zhao W, Zhong Z, Xie X, et al. Relation Between Chest CT Findings and Clinical Conditions of Coronavirus Disease (COVID-19) Pneumonia: A Multicenter Study. AJR Am J Roentgenol 2020;(3):1-6.

92. Ai T, Yang Z, Hou H, et al. Correlation of chest $\mathrm{CT}$ and RT-PCR testing in coronavirus disease 2019 (COVID-19) in China: a report of 1014 cases. Radiology 2020 doi: 10.1148/radiol.2020200642.

93. W.-Q. Zhan, M.-D. Li, M. Xu, Y.-B. LuSuccessful treatment of COVID-19 using extracorporeal membrane oxygenation, a case report. Eur Rev Med Pharmacol Sci. 2020; 24 (6):3385-3389 DOI: 10.26355/eurrev_202003_20705

94. FDA. Coronavirus (COVID-19) Update: FDA Issues Emergency Use Authorization for Potential COVID-19 Treatment. fda.gov. Available at https://www.fda.gov/news- 
events/press-announcements/coronavirus-covid-19-updatefda-issues-emergency-useauthorization-potential-covid-19treatment. May 01, 2020; Accessed: May 01, 2020.

95. FDA. FACT SHEET FOR HEALTH CARE PROVIDERS EMERGENCY USE AUTHORIZATION (EUA) OF REMDESIVIR (GS5734TM). fda.gov. Available at https:// www.fda.gov/media/137566/download. May 1, 2020; Accessed: May 1, 2020.

96. Beigel JH, Tomashek KM, Dodd LE, Mehta AK, Zingman BS, Kalil AC, et al. Remdesivir for the Treatment of Covid19 - Preliminary Report (ACTT-1 Study). N Engl J Med. 2020 May 22.

97. Rajter JC, Sherman M, Fatteh N, Vogel F, Sacks J, Rajter JJ. ICON (Ivermectin in COvid Nineteen) study: Use of ivermectin is associated with lower mortality in hospitalized patients with COVID-19. medRxiv. 2020 Jun 09.

98. FDA cautions against use of hydroxychloroquine or chloroquine for COVID-19 outside of the hospital setting or a clinical trial due to risk of heart rhythm problems. US Food \& Drug Administration. 2020 Apr 24. Available at

99. University of Minnesota. Losartan for Patients With COVID-19 Not Requiring Hospitalization (NCT04311177). ClinicalTrials.gov. Available at https:// www.clinicaltrials.gov/ct2/show/NCT04311177? term= NCT04311177\&draw=2\&rank=1. 2020 Mar 17; Accessed: March 27, 2020

100. [Guideline] NIH. Potential Antiviral Drugs Under Evaluation for the treatment of COVID-19. COVID-19 Treatment Guidelines. Available at https://www.covid19 treatmentguidelines.nih.gov/antiviral-therapy/. 2020 Jun 11; Accessed: June 16, 2020

101. Lansbury L, Rodrigo C, Leonardi-Bee J,Nguyen-Van-Tam J, Lim WS. Corticosteroids as adjunctive therapy in the treatment of influenza. Cochrane Database Syst Rev2019;2:CD010406.

102. Delaney JW, Pinto R, Long J, et al. The influence of corticosteroid treatment on the outcome of influenza A(H1N1pdm09)-related critical illness. Crit Care 2016;20:75. Lansbury L, Rodrigo C, Leonardi-Bee J, Nguyen-Van-Tam J, Lim WS. Corticosteroids as adjunctive therapy in the treatment of influenza. Cochrane Database Syst Rev 2019;2:CD010406.

103. National Institute for Health and Care Excellence. Preterm labour and birth 2019 [updated August. Available from: https://www.nice.org.uk/guidance/ng25.

104. Tim Locke UK COVID-19 Update: Dexamethasone 'Breakthrough', BAME Report Part 2 June 16, 2020

105. Gudbjartsson DF, Helgason A, Jonsson H, et al. Spread of SARS-CoV-2 in the Icelandic Population. $N$ Engl J Med. 2020;382:2302-2315.

106. Otto MA. Wuhan Virus: What Clinicians Need to Know. Medscape Medical News. Jan 27,2020. Available at https:/ /www.medscape.com/viewarticle/924268. January 27, 2020.

107. Feuer W, Higgins-Dunn N, Lovelace B. US now has more coronavirus cases than either China or Italy. CNBC. Available at https://www.cnbc.com/2020/03/26/usa-nowhas-more-coronavirus-cases-than-either-china-oritaly.html. March 26, 2020; Accessed: March 27, 2020.
108. CDC. Coronavirus Disease 2019: Pandemic Planning Scenarios. CDC. Available at https://www.cdc.gov/ coronavirus/2019-ncov/hcp/planning-scenarios.html. May 20, 2020; Accessed: May 26, 2020.

109. Royal College of Obstetricians \& Gynaecologists. Reducing the Risk of Venous Thromboembolism during Pregnancy and the Puerperium 2015 [updated April. Available from: https://www.rcog.org.uk/globalassets/ documents/guidelines/ gtg-37a.pdf].

110. Thrombosis UK. Practical guidance for the prevention of thrombosis and management of coagulopathy and disseminated intravascular coagulation of patients infected with COVID-19. 2020 [Available from: https:// thrombosisuk.org/covid-19-thrombosis.php] accessed 07 April 2020.

111. National Institute for Health and Care Excellence. COVID19 rapid guideline: acute myocardial injury. 2020 [updated 23 April 2020; available from: https://www.nice.org.uk/ guidance/ng171] accessed 27 April 2020.

112. Li L, Zhang W, Hu Y, et al. Effect of Convalescent Plasma Therapy on Time to Clinical Improvement in Patients With Severe and Life-threatening COVID-19A Randomized Clinical Trial. JAMA. Published online June 3, 2020. doi:10.1001/jama.2020.10044

113. Bloch EM, Shoham S, Casadevall A, Sachais BS, Shaz B, Winters JL, et al. Deployment of convalescent plasma for the prevention and treatment of COVID-19. J Clin Invest. $2020 ; 130(6): 2757-2765$.

114. The Society for Obstetric Anesthesia and Perinatology. Interim considerations for obstetric anesthesia care related to COVID19. Available at: https://soap.org/education/ provider-education/expert-summaries/interimconsiderationsfor-obstetric-anesthesia-carerelated-to-covid19/. Accessed March 23,2020. Continue to breastfeed while taking care with hygiene.

115. Boelig RC, Manuck T, Oliver EA, Mascio DD et al. Labor and delivery guidance for COVID-19. AJOG MFM 2020.

116. UNICEF/UNI 166592/Liu https://www. google.com/ search? $\mathrm{q}=$ Continue + to + breastfeed + while + taking + care + with + hygiene\&oq $=$ Continue + to + breastfeed + while + taking + care + with + hygiene\&aqs $=$ chrome. 69 i57. 2343 j0j8\& sourceid $=$ chrome \&ie $=$ UTF -8

117. Coronavirus Disease (COVID-19) and Breastfeeding. Centre for disease control and prevention CDC 24/7:Saving lives, protecting people https://www .cdc.gov/breastfeeding/ breastfeeding-special-circumstances/maternal-or-infantillnesses/covid-19-and breastfeeding.html

118. World Health Organization. Clinical management of severe acute respiratory infection (SARI) when COVID-19 disease is suspected: interim guidance, 13 March 2020. Geneva: WHO; 2020. Available from:https://apps.who.int/iris/handle/ $10665 / 331446$

119. Wang L, Shi Y, Xiao T, Fu J, Feng X, Mu D, et al. Chinese expert consensus on the perinatal and neonatal management for the prevention and control of the 2019 novel coronavirus infection (First edition). Ann Transl Med. 2020;8(3):47. doi: 10.21037/atm.2020.02.202020 